\title{
ACERCA DE LA PRENSA Y OTROS MEDIOS \\ COMO FUENTE PARA EL ESTUDIO \\ HISTÓRICO DE LOS CONCEPTOS \\ ESTRUCTURALES DEL MUNDO \\ DE LA COMUNICACIÓN
}

\author{
Javier Fernández Sebastián \\ Universidad del País Vasco
}

Siguiendo la amable invitación de los organizadores de estas jornadas, quisiera centrar mi intervención en esta mesa redonda en algunos puntos que, a mi modo de ver, pudieran servir para mejorar nuestro estudio de los medios de comunicación en el pasado y, sobre todo, para abordarlos desde un punto de vista más histórico. Me refiero en concreto a las grandes posibilidades que nos ofrece la prensa escrita (pienso sobre todo en los siglos XVIII y xIx, la época que mejor conozco, ya que mis reflexiones parten ineludiblemente de mi propia experiencia como investigador) para analizar el surgimiento y evolución histórica de los grandes conceptos de base que subyacen al mundo de la transmisión de informaciones y a la comunicación social a lo largo de los últimos siglos.

Las reflexiones que aquí planteo, con la esperanza de que puedan resultar de alguna utilidad a los investigadores gallegos en historia de la prensa y de la comunicación social, son como digo el resultado de una experiencia investigadora relativamente dilatada, enfocada sobre todo desde la perspectiva de la historia del pensamiento político, que es la disciplina académica de la que procedo y en la que me he especializado desde hace años.

En mis primeros trabajos para la preparación de la que luego sería mi tesis de doctorado -titulada Prensa y publicística vasconavarra en la crisis del Antiguo Régimen. Los orígenes del pe- 
riodismo y el despliegue de las ideologías políticas- me aproximé a la prensa periódica en busca de un tipo de fuentes que me permitieran acceder a lo que llamé una «historia social de las ideas», esto es, al pensamiento político tal cual aparece «disuelto» en la sociedad, disperso en multitud de folletos, opúsculos, pequeñas publicaciones periódicas, alocuciones y proclamas, reuniones de clubs y sociedades patrióticas, oratoria parlamentaria e, incluso, pliegos de cordel $^{1}$. Un tipo de pensamiento que, a diferencia de las doctrinas de los autores clásicos del programa de la materia universitaria Historia de las Ideas Políticas, no se presenta de manera ordenada, estructurada y coherente, a manera de un repertorio de sistemas filosóficos cerrados, sino más bien de manera caótica, como una respuesta dilatada, múltiple y cambiante -o más bien como una larga serie de réplicas y contrarréplicas- a los desafíos y tensiones de la vida política cotidiana, y a la vez como un reflejo de las disensiones ideológicas entre los diversos agentes políticos y sociales. Como una suerte de «gran diálogo»o «permanente debate social», en suma.

Además, siempre me pareció que no debemos ver los libros y los periódicos como simples «contenedores de ideas», y desde ese punto de vista es fundamental complementar el análisis de los discursos con la historia de la comunicación social (incluyendo la historia del libro y el mundo de la edición, el proceso de profesionalización de autores y periodistas, la evolución de los modos de lectura, etc.). En este sentido, la historia intelectual que sólo atiende al mundo del «pensamiento puro», esto es, a las ideas abstractas, social y culturalmente desencarnadas, queda a mi modo de ver francamente coja: como historiador, siempre pensé que es necesario prestar mucha más atención al alcance y modalidades de la difusión de escritos e impresos, y no sólo a los contenidos «ideológicos» que se vehiculan a través de los diferentes medios ${ }^{2}$.

1. Dos años después de su defensa, publiqué la segunda parte de esta tesis de doctorado bajo el título La génesis del fuerismo. Prensa e ideas políticas en la crisis del Antiguo Régimen (País Vasco, 1750-1840), Madrid, Siglo XXI de España, 1991.

2. Así, desde el punto de vista de la historia política y cultural, la relevancia de un texto se mide sobre todo en términos de difusión y de influencia, mientras que desde el punto de vista de la clásica historia intelectual ese dato resulta mucho menos 
Por lo demás, la carencia en esas fechas -mediados de los años ochenta- de catálogos hemerográficos adecuados relativos al País Vasco nos obligaba entonces a los que nos interesábamos por la prensa esencialmente como fuente, esto es, a quienes pretendíamos hacer más bien historia a través de la prensa que propiamente historia de la prensa, a dedicar gran parte de nuestros esfuerzos a la localización, inventariado y catalogación de muchos de esos títulos, en su mayoría casi completamente desconocidos (llegando incluso a propiciar la reedición en facsímil de algunos de aquellos periódicos que por su carácter pionero entendíamos merecían ser conocidos del público de nuestros días ${ }^{3}$ ). Desde entonces, por fortuna, las cosas han cambiado mucho y la historiografía vasca dispone desde hace tiempo de algunos trabajos catalográficos ejemplares, entre ellos el repertorio preparado por Adolfo Ruiz de Gauna, que incluye los datos más significativos de cada publicación y la localización de la práctica totalidad de la prensa periódica de la región ${ }^{4}$.

Desde el principio, pues, mi interés por la cultura periodística se orientó, sobre todo, al estudio de la opinión pública, por incipiente que esta fuese. Y es así como comencé a interesarme

significativo: ciertas obras muy poco leídas pueden ser consideradas de enorme importancia a pesar de su escasa difusión. Quentin Skinner aludía recientemente a los Principia Mathematica de Newton como un «ejemplo obvio» al respecto: "On Intellectual History and the History of Books», Contributions to the History of Concepts, 1/1 (2005), 29-36. Sobre la posibilidad de combinar análisis del discurso e historia cultural véase también, en la misma publicación, el artículo de Robert Darnton «Discourse and Diffusion», ibidem, 21-28.

3. «El Bascongado» (1813-1814). Primer periódico de Bilbao, Bilbao, Parlamento Vasco, 1989. El "Correo de Vitoria» (1813-1814) y los orígenes del periodismo en Alava, Vitoria, Ayuntamiento de Vitoria-Gasteiz, 1993. En ambos casos, la edición facsimilar y el estudio introductorio corrieron a cargo del autor de estas líneas.

4. Adolfo Ruiz de Gauna, Catálogo de publicaciones periódicas vascas de los siglos XIX y xx, San Sebastián, Eusko Ikaskuntza-Sociedad de Estudios Vascos, 1991. Otros catálogos recientes referentes tanto a la prensa vasca como a la navarra: Catálogo de publicaciones periódicas vascas, Vitoria-Gasteiz, Parlamento Vasco, 1986; J. Elena Santamaría Blasco, Catálogo de publicaciones periódicas impresas en Navarra, Pamplona, Gobierno de Navarra, 1990; Gabriel Imbuluzqueta, Periódicos navarros del siglo XIX, Pamplona, Gobierno de Navarra, 1993; Javier Díaz Noci, Euskarazko aldizkari, almanaka eta egutegien erroldea (1834-1959), San Sebastián, Eusko Ikaskuntza-Sociedad de Estudios Vascos, 1994. 
por lo que esos primeros periódicos decían acerca de sí mismos y de la actividad que desempeñaban. No tardé en descubrir que en las páginas de la prensa, incluso en sus primeras etapas, se almacenaban informaciones preciosas para el estudio del periodismo mismo, en especial acerca de la cristalización de los conceptos básicos que estructuran las prácticas comunicativas, y de las estrategias que los publicistas desplegaron para llegar mejor a los lectores y hacer sus escritos más interesantes y accesibles a públicos cada vez más amplios.

Cuando, al cabo de algunos años, me hice cargo, en colaboración con mi colega y amigo Juan Francisco Fuentes, de la redacción de un manual universitario sobre historia del periodismo en España, nuestro objetivo desde el principio no fue escribir una historia meramente informativa de los periódicos y medios de comunicación, sino que preferimos inscribir nuestro trabajo de síntesis didáctica en un marco metodológico e interpretativo más amplio, centrándonos en la interdependencia entre la historia política y cultural y los medios de comunicación social, que a menudo han jugado en la historia de nuestro país un papel fundamental (incluso, en ocasiones, decisivo). De ahí el subtítulo que pusimos a nuestra obra: Prensa, política y opinión pública en la España contemporánea 5 .

Conviene tener en cuenta que conceptos tan básicos para nuestro quehacer investigador como lo son periodismo, publicidad, opinión pública, escritor, público, información o comunicación obviamente no han existido siempre. Por el contrario, han tenido una gestación histórica en circunstancias concretas que es importante conocer y analizar ${ }^{6}$. Rastrear sus orígenes y entender bien el contexto en el que estos conceptos nacieron y se fueron poco a

5. Historia del periodismo español. Prensa, política y opinión pública en la España contemporánea, Madrid, Editorial Síntesis, 1997. Aunque ambos autores nos responsabilizamos de la obra en su integridad, Juan Francisco Fuentes se hizo cargo de la redacción de los capítulos relativos al siglo xx, asumiendo yo mismo la redacción de los capítulos correspondientes a los siglos XVIII y XIX.

6. Por no hablar de otro tipo de nociones «internas» más concretas, a las que se refería María Cruz Seoane en su intervención en este mismo foro, específicas en este caso del «tecnolecto» correspondiente al periodismo impreso, como son artículo, columna, editorial, folletín, etc. 
poco moldeando de una u otra manera es una necesidad para todo aquel que quiera contribuir a la recuperación de «la memoria comunicativa» (esto es, hacer el inventario de los medios y de su uso) y, sobre todo, para quien pretenda escribir una historia que intente ser verdaderamente comprensiva (i. e., próxima a la mentalidad de los agentes históricos involucrados) del periodismo y de la comunicación social en Galicia o en cualquier otro ámbito territorial.

A continuación pondré algunos ejemplos, tomados en parte de algunas obras ya publicadas ${ }^{7}$, que permitan al lector hacerse una idea más precisa de qué hablamos cuando decimos que es necesario rastrear en la prensa cómo se fueron conformando algunos conceptos fundamentales. Sostenemos, en efecto, que una lectura atenta de las fuentes hemerográficas permite al investigador detectar las pequeñas o grandes innovaciones semánticas que en este terreno se van produciendo con el paso de los años. En concreto, los ejemplos que siguen se refieren, sobre todo, al surgimiento del concepto de periodismo.

A este respecto, la década de los 80 del siglo xviII resulta decisiva. Es entonces, en efecto, en esa década dorada del periodismo dieciochesco (no por casualidad la palabra periodista empieza entonces a generalizarse, en detrimento de voces como gacetero, diarista, jornalista, papelista o novelista, que poco a poco irán cayendo en desuso) cuando Carlos III regula por vez primera de manera específica (R. O. de 19-V-1785) ese novedoso "género de escritos» doblemente calificado por el P. Juan Andrés como «nueva clase de literatura» $\mathrm{y}$ «nuevo ramo del comercio literario y económico», que será ensalzado a menudo por su importante contribución a «los progresos de las ciencias y las artes» (Ensayo de una biblioteca

7. La mayoría de los ejemplos que aquí traemos a colación se han extraído de nuestras voces «Opinión pública» y «Periodismo» del Diccionario político y social del siglo XIX español, Javier Fernández Sebastián y Juan Francisco Fuentes, dirs., Madrid, Alianza Editorial, 2002. Pueden encontrarse muchos más ejemplos similares en Juan Francisco Fuentes y Javier Fernández Sebastián, Historia del periodismo español. Prensa, política y opinión pública en la España contemporánea, Madrid, Editorial Síntesis, 1997, especialmente en los apéndices documentales que siguen a cada capítulo de esta obra. 
española de los mejores escritores del reinado de Carlos III, 1787, IV, 176-98, donde Juan Sempere y Guarinos efectúa un primer balance histórico del periodismo español, lo que no deja de ser un reconocimiento implícito del largo camino recorrido). Poco antes, el más prestigioso de nuestros papeles periódicos del setecientos había sometido a auto-análisis su propia actividad. Brevedad, concisión, variedad, espíritu crítico, amplia difusión gracias a su bajo coste y a las múltiples conversaciones que su lectura suscita, son algunos de los rasgos que caracterizan a unas modestas producciones intelectuales que no por efímeras encierran menor dificultad para sus autores, y cuyas miras políticas de fondo no se le ocultan al redactor: "preparar los ánimos para las reformas que [el gobierno] medita» y hacer ver al público «su acierto y la conexión que [tales medidas] tienen con su felicidad» (El Censor, CXXXVII, 28-XII-1786, pp. 86-96).

Para entonces, la gran mayoría de los intelectuales ilustrados -que inicialmente solían desconfiar de las obras periódicas, a las que acusaban generalmente de superficialidad-asignan a la prensa un papel esencialmente educativo e indoctrinador. Puente de dirección única entre el poder ilustrado y los ciudadanos, su eminente función de guías y conformadores de la opinión pública, sin embargo, se verá trastocada por la eclosión de la política en los años de la guerra de la Independencia. La irrupción de un nuevo ideal de educación política generalizada, que va más allá de la tutela por parte de las autoridades, es patente en muchos textos periodísticos del momento (como sucede con el Semanario Patriótico, de Quintana, cuya voluntad pedagógico-política queda bien patente desde el primer número: su tarea sistemática de explicación y popularización de los conceptos políticos y jurídicos fundamentales del pensamiento liberal resulta, a este respecto, ejemplar). El ideal educativo ilustrado se ha trasladado bruscamente desde la primavera de 1808 al terreno específico de la política. «La España necesitaba desde mucho tiempo el auxilio de estos conductores literarios», leemos en un periódico liberal gallego, «[gracias a los cuales] en medio pliego se habla de cosas que hasta hace poco no se leían sino en tomazos de a folio (...) 
[de modo que por ese medio llegan a] las manos del artesano los conocimientos sabios y literarios» (El Patriota Compostelano, 11-VIII-1811 ${ }^{8}$.

Poco antes, un clérigo tradicionalista había subrayado igualmente en el prospecto de un periódico de Valencia que, a diferencia de los extensos tratados sólo al alcance de los lectores doctos, el periodismo tenía algunas ventajas muy estimables: «es breve, sencillo y deleitable al oído por la variedad de sucesos, máximas y doctrina. Corre por las calles y plazas; se lee en los concursos, y en el seno de las familias. Pasa de mano en mano, se puede meditar, se repite a toda hora y se conserva cuanto se quiere» (P. Manuel Traggia, El Vencedor Católico, 1809).

Y si, como se ha visto, El Censor de Cañuelo había encarecido en la segunda mitad de la década de 1780 algunas virtudes del incipiente periodismo dieciochesco, algunos decenios más tarde, durante el trienio liberal (1820-1823) encontramos en las páginas de otra publicación homónima madrileña, de matiz liberal moderado, reflexiones teóricas de cierta enjundia acerca del papel de la prensa en los nuevos tiempos (que por momentos incluye algo parecido a lo que pudiéramos llamar un esbozo de deontología del periodista, con el cortejo de deberes y de obligaciones supuestamente inherentes al oficio). Según El Censor de A. Lista (tomo XVI, núm. 93, 11-V-1822, 171), en efecto, junto a la labor pedagógica y noticiera, correspondería a los periódicos cierta forma de control sobre los gobernantes, pero además se trataba de hacerles llegar las luces emanadas de los más capaces de entre los gobernados. Se trataba, en suma, de activar al máximo la relación mutua entre las autoridades y los escritores públicos, que deben colaborar con aquéllas indirectamente por medio de sus sugerencias y de sus críticas. Y para ello se hacía necesario,

8. Compárese la actitud de los redactores de este periódico con la que apenas un decenio antes había manifestado Valle-Inclán en el discurso de apertura del primer periódico publicado en la misma ciudad de Santiago, orientada sobre todo a «reprehender los errores introducidos bajo el nombre de costumbre, e instruir en todas las materias políticas y literarias» (El Catón Compostelano [1800], vol. I. Facsímile y vol. II. Estudios, Santiago de Compostela, Consello da Cultura Galega, 2000). 
desde luego, contar en la base del sistema con un público, esto es, con un volumen de «semi-sabios», lectores de prensa periódica, lo más amplio e ilustrado posible ${ }^{9}$.

El trienio liberal es también el momento, sin embargo, en que un pathos romántico se apodera de gran parte de las publicaciones, y el impulso didáctico y racionalista característico de la Ilustración empieza a ser sustituido por un nuevo lenguaje mucho más apasionado, en el que la argumentación razonada deja paso cada vez con mayor frecuencia a la ironía y al sarcasmo (cuando no a la difamación y el escarnio). Es entonces cuando empieza a gestarse uno de los lugares comunes más reiterados sobre este tema a lo largo de la centuria: «La prensa debió ser siempre vehículo de ilustración, escuela de moralidad y de pública enseñanza; y en vez de llenar tan dignos objetos, fue sólo constante motivo

9. Como hemos argumentado con más detalle en otro lugar, la aparición de esta suerte de «clase media intelectual» constituida por un contingente más o menos amplio de «medio-doctos» o «semi-sabios», aficionados a la lectura de opúsculos y periódicos, supone una importante novedad sociocultural que se hace notar en la vida española desde mediados del siglo xviII. Una novedad que está en la base de esa ampliación sustancial de la restringida Respublica literaria y subsiguiente apertura de una nueva esfera de publicidad política que empezará a ser conocida como opinión pública. No por casualidad, a finales del siglo xvIII observaba un alto funcionario de imprentas de la administración borbónica española que «estamos en un siglo en que abunda tanto el espíritu de novedad y no poco número de semi-sabios...» (AHN, Consejos, 5560-II, 94, cit. en Esteban Conde Naranjo, «Cultivar la opinión, una metáfora de la España ilustrada», Giornale di Storia Costituzionale, 6 (2003), p. 155). Sobre esta cuestión puede verse nuestro trabajo: «De la 'República de las letras' a la 'opinión pública': intelectuales y política en España (1700-1850)», en Historia, filosofía y política en la Europa moderna y contemporánea, León, Universidad de León y Max-Planck-Institut für Geschichte, 2004, pp. 13-40. Entre los numerosos trabajos que hemos dedicado en los últimos años al examen del concepto de opinión pública destacamos los siguientes: "The Awakening of Public Opinion in Spain. The Rise of a New Power and the Sociogenesis of a Concept», en Opinion, Peter-Eckhard Knabe, ed., Berlín, Concepts and Symbols of the Eighteenth Century Europe, Berlin, Verlag Arno Spitz, 2000, pp. 45-79; «El imperio de la opinión pública según Flórez Estrada», en Álvaro Flórez Estrada (1766-1853). Política, Economía, Sociedad, Joaquín Varela Suanzes-Carpegna, coord., Oviedo, Junta General del Principado de Asturias, 2004, pp. 335-398; «Sobre la construcción, apogeo y crisis del paradigma liberal de la opinión pública: ¿un concepto político euroamericano?», Historia Contemporánea, núm. 27 (2004), pp. 539-563; así como el volumen colectivo L'avènement de l'opinion publique. Europe et Amérique XVIII-XIX ${ }^{e}$ siècles, Javier Fernández Sebastián y Joëlle Chassin, eds., París, L'Harmattan, 2004. 
de escándalo, tea arrojada directamente sobre la sociedad para perturbarla, abrasarla y consumirla» ${ }^{10}$. Según este reproche - mil veces repetido con ligeras variaciones por otros muchos autores (Balmes, Donoso, Mesonero, Rico y Amat, Mañé y Flaquer y tutti quanti)-, el espíritu de partido, la demagogia y la pasión política habrían pervertido muy pronto los fines formativos y benéficos que a comienzos de siglo se asignaba generalmente a la prensa periódica. La falta de independencia, mesura y ecuanimidad suele considerarse en parte consecuencia de la escasa preparación intelectual de quienes profesan el periodismo, pues, como escribe el joven Donoso Cortés en El Correo Nacional, «entre nosotros un periódico no es una empresa literaria confiada a los que estudian y saben, sino una máquina de guerra que conducen y dirigen los osados» (1838). Y es que la mayoría de los periódicos, en esas primeras décadas del xix, son, como es sabido, órganos -o más bien núcleo- de los incipientes partidos, y estamos todavía lejos del periodismo esencialmente informativo, mucho más profesionalizado y ecuánime, que sólo se abrirá paso en el último cuarto de la centuria.

Podríamos seguir citando algunas jugosas reflexiones de Larra sobre el periodismo como "síntoma de la vida moderna», factor decisivo del progreso intelectual, exponente de la clase media ilustrada y sobre todo como uno de los resultados de la creciente celeridad del siglo -el libro es al periódico, dice, lo que el carromato a la diligencia-, pero no se trata de seguir acumulando testimonios extraídos en gran medida de la prensa sobre la prensa misma. Lo que intentábamos con estas pinceladas era simplemente señalar el camino y mostrar que, sin duda también en la prensa gallega (y también en otros medios), es posible rastrear la gestación y evolución del concepto y valoración del periodismo como actividad cultural y económica, del periódico como medio y formato específico para la transmisión de noticias y opiniones, o, en fin, del periodista como profesional dedicado a ese cometido. 
El propio concepto de comunicación que da título a estas jornadas es también, por supuesto, un concepto histórico. Y tal vez no esté de más señalar que, a lo largo del siglo xx, el término comunicación ha ido ampliando considerablemente su campo semántico, pasando de designar casi exclusivamente los medios de transporte y locomoción, y los aparatos técnicos para el intercambio de mensajes (ferrocarriles, correos, telégrafos, teléfono, etc.), a los llamados medios de comunicación de masas o medios de comunicación social (prensa, radio y televisión fundamentalmente, aunque en los últimos años se ha venido a añadir el mundo de Internet, en pleno proceso de expansión). No deja de ser significativo al respecto que desde comienzos de los noventa las antiguas facultades de Periodismo o de Ciencias de la Información hayan pasado a denominarse facultades de Ciencias de la Comunicación. Una transformación en el vocabulario oficial que sin duda responde a importantes cambios conceptuales y sociales de base. 